Bryant University

Bryant Digital Repository

Spring 2021

\title{
Anything He Can Do, She Can Do Better: Children's Attitudes About Gender and Occupations
}

Ryan Brown

Nanci Weinberger

Bryant University, nweinber@bryant.edu

Follow this and additional works at: https://digitalcommons.bryant.edu/apjou

Part of the Other Psychology Commons

\section{Recommended Citation}

Brown, Ryan and Weinberger, Nanci, "Anything He Can Do, She Can Do Better: Children's Attitudes About Gender and Occupations" (2021). Applied Psychology Journal Articles. Paper 52.

https://digitalcommons.bryant.edu/apjou/52

This Article is brought to you for free and open access by the Applied Psychology Faculty Publications and Research at Bryant Digital Repository. It has been accepted for inclusion in Applied Psychology Journal Articles by an authorized administrator of Bryant Digital Repository. For more information, please contact dcommons@bryant.edu. 


\title{
Anything He Can Do, She Can Do Better: Children's Attitudes About Gender and Occupations
}

\author{
Ryan Brown ${ }^{1}$ and Nanci Weinberger ${ }^{2 *}$ \\ 'Department of Psychology, Bryant University \\ ${ }^{2}$ Department of Psychology, Center for Health and Behavioral Sciences, Bryant University
}

\begin{abstract}
Children's career aspirations are affected by cultural stereotypes about gender. We investigated rudimentary implicit associations and explicit gender attitudes about occupations with a diverse sample of fifty-eight (29 girls, 29 boys) 10-year-old children. We tested implicit gender associations using an adapted auditory Stroop task and tested explicit gender attitudes using the Gender-Stereotyped Attitude Scale for Children (GASC). We also modified a version of the GASC to assess children's attitudes about a female and a male firefighter-paramedic seen in a brief video. Children also judged the firefighter-paramedics' job skills. Children did not display implicit associations between occupations and one's gender based on differences in the response times between the congruent and incongruent test trials that paired male and female voices with occupations, $t(1762)=0.65$, $p=.52, d=0.03$. Auditory voice stimuli might have confounded the tested associations between gender and occupations. The GASC findings highlighted gender stereotype flexibility about men and women. Girls were more flexible than boys on the job component of the GASC, $t(56)=-2.12$, $p=.039, d=0.55$. The level of children's gender stereotype flexibility varied by occupation. Children exhibited the most flexibility for who should be a doctor and the least flexibility for who should be a ballet dancer/teacher. Lastly, we assessed attitudes toward the specific woman featured in the video; children overwhelmingly saw her as a potentially good fire chief (vs. the man featured in the video; $91 \%$ selected Kate or both for who would be a better fire chief).
\end{abstract}

Keywords: children, gender attitudes, occupations, counterstereotypical, stereotype flexibility

SPRING 2021

PSI CHI

JOURNAL OF

PSYCHOLOGICAL RESEARCH
G ender is one of the most salient social categories; all human cultures identify, socialize, and prescribe roles for individuals based on their gender (Glick \& Fiske, 1999). Children demonstrate their ability to identify their own gender and readily determine which clusters of behaviors are associated with their own gender (Halim et al., 2014). Moreover, children sanction other children who are seen to be violating genderbased norms of behavior (Skočajić et al., 2019). Among the many potential consequences of relying on gender stereotypes are the limits that adults and children place on their career paths. Even young children base their career aspirations on gender stereotypes (Hayes et al., 2018; Liben et al., 2001).

The well-established body of research assessing children's explicitly stated attitudes about gender have expanded in recent years to more fully include children's implicit attitudes (Skowronski \& Lawrence, 2001). Less is known about children's implicit gender attitudes about occupations as compared with their explicit attitudes about occupations. The first goal of the current study was to examine 10-year-old children's rudimentary implicit 
and explicit gender attitudes with a focus on occupations. By middle childhood, children become more flexible about their explicit gender attitudes about occupations (Garrett et al., 1977; Ruble et al., 2006). This flexibility hints at the possibility that there are circumstances, such as exposure to counter-stereotypical models, that can augment children's views about gender and occupations. Therefore, the second goal of the current study was to examine how children evaluate a woman and a man who were realistically portrayed in the same stereotypically male occupation.

\section{Children's Attitudes About Gender and Occupations}

Considering that gender stereotypes may shape occupational aspirations, it is useful to see how children associate gender with occupations. Children ascribe more restrictive occupational roles for men than women (Weisgram et al., 2010; Wilbourn \& Kee, 2010). For example, Blakemore (2003) found that 7- to 10-year-olds were more negative in their appraisals of male nurses compared to female nurses. When faced with nontraditional or counter stereotypical examples, individuals often explicitly label neutral words with a feminine or masculine modifier that marks the perceived abnormality of the person-job pairing (e.g., "female doctor" or "male nurse"; Liben et al., 2002). Similarly, Vervecken \& Hannover (2015) found that, among 6- to 12-year-old children, "linguistic feminization" of stereotypically male occupations increased children's self-efficacy and the ascription of higher job accessibility.

Children as young as 4 and 5 years old demonstrate stereotyped occupational goals that suggest that their behaviors and preferences are informed by their early accumulation of gender knowledge (Huston, 1983). Stereotyped knowledge of child and adult occupations increases rapidly between ages 3 to 5 and hits a ceiling by kindergarten or first grade. Until age 7 or 8 , stereotypes are held rigidly, but then flexibility increases dramatically (Ruble et al., 2006). For example, older elementary school children were more likely than younger elementary school children to consider occupations as appropriate for both genders instead of just one gender (Garrett et al., 1977). This may be due to older children's ability to identify gender stereotypes as such, whereas younger children may also be less likely to attend to counter stereotypical information (Carter \& Patterson, 1982). As children become more flexible about gender attitudes, they begin to recognize that occupations can be suitable for both men and women.

Children and adults rely on cultural, situational, and historical factors to inform their acquisition and expression of gender-based occupation stereotypes. A potent demonstration of an occupational stereotype was found in the seminal Draw a Scientist study of nearly 5,000 young children; only 28 children, all girls, drew a female scientist (Chambers, 1983). A meta-analysis identified a decrease in recent decades in the proportion of children drawing a male versus a female scientist; however, the rates of drawing a male scientist continue to be much higher than a female scientist (Miller et al., 2018). Thus, we aimed to study children's conceptions of these roles in society to understand the implications of such gender occupation stereotypes.

Eagly (1987) identified children's low selfefficacy beliefs toward occupations that are stereotypically male. During middle childhood, children also come to learn that gender-typical occupations are characterized by different values also associated with gender (Hayes et al., 2018). Children's initial limited knowledge that men and women occupy positions that differ in attributes such as power, income, altruism, and family flexibility grow significantly in middle childhood (Hayes et al., 2018). This can be compounded with other gender norms. For example, parents explain their children's success differently based on their gender such that boys' success is attributed to ability, whereas girls' success is explained by effort (Räty et al., 2002). Yet, parents and educators can also help children to develop more egalitarian views and build skills that can foster diverse occupational interests. For example, early career preparation and skill development can be realized in programs such as a Lego engineering summer camp (Holler, 2013). Unfortunately, stereotypes can persist even in specially designed programs to welcome all children, potentially explaining the gender imbalances found among enrolled children.

In addition to the impact of explicit attitudes, implicit attitudes may also be contributing to children's behavioral choices. Implicit attitudes are often not correlated with one's explicit attitudes (Skowronski \& Lawrence, 2001). Implicit attitudes represent "introspectively unidentified (or inaccurately identified) traces of past experience that mediate favorable or unfavorable feeling, thought, or action toward social objects" (Greenwald \& Banaji, 1995, p. 8). People's implicit biases are
SPRING 2021

PSI CHI JOURNAL OF PSYCHOLOGICAL RESEARCH 
potent enough to uniquely predict prejudiced behavior in both children and adults (Dunham et al., 2011; Greenwald et al., 2009).

Measurements of implicit associations differ from the vast array of measures of explicit attitudes. Measures of implicit associations typically include processing speed and sometimes memory recall accuracy of stereotyped pairings as compared with counter-stereotyped pairings such as male or female name and occupation (e.g., Wilbourn \& Kee, 2010). In contrast, measures of explicit attitudes generally involve direct questions such as own-gender and other gender evaluations and self-reported adherence or resistance to gender stereotyped behavior as well as other ratings (Mulvey \& Killen, 2015).

One of the most frequently used implicit measures to date is the Implicit Association Test (IAT). The IAT, developed by Greenwald et al. (1998), measures the strength of associations between categorical concepts (e.g., women, men) and attributes including evaluations (e.g., good, bad; Carney et al., 2007; Rae \& Olson, 2018). Many applications of the IAT assume that the IAT can predict discrimination in the real world; however, there is ongoing controversy about the predictive validity of the IAT as it does not link with behavior any more strongly than explicit attitudes in some circumstances (Oswald et al., 2013). Because the IAT was primarily used to study, and hopefully predict, implicit racial attitudes that predict discriminatory behavior, these criticisms call into question conclusions that researchers draw from these studies. However, in this study, we were more interested in the associations themselves and how those implicit associations may reflect children's perceptions of counter-stereotypical careers.

Children's implicit associations of math with boys may contribute to early differences in girls' beliefs that STEM careers are for them. Cvencek et al, (2011) observed both implicit and explicit mathgender stereotypes, previously identified in adults, in elementary school children using a child-specific IAT. Gender differences in these math-gender stereotypes appeared for children in Grades 1 and 2. Boys in the Cvencek et al. study associated me with math more than the girls, despite that there are no significant differences on math achievement tests in elementary school (Hyde et al., 2008). These results suggest that, when children hold stereotypes (e.g., "Math is for boys") as well as their gender identity (e.g., "I am a girl"), the combination primes negative evaluations of one's own ability and belongingness in a particular domain (e.g., "Math isn't for me").
Most et al. (2007) developed an auditory Stroop task to also evaluate implicit gender schema contents. The traditional Stroop task causes cognitive interference by forcing participants to attend to a specified feature of a stimulus, such as reading the name of a color while the word is printed in an interfering ink color (i.e., the word "blue" may be printed in green ink; Stroop, 1935). In the Most et al. (2007) auditory Stroop task, the research protocol is simplified for young participants; it does not require any reading. In addition, the auditory Stroop procedure asks participants to identify only one thing about the stimulus: if the voice they hear through headphones is a male voice or a female voice.

Among adults, response times to an auditory Stroop task including incongruent word-voice pairs (e.g., male voice paired with female name) were significantly longer than that of congruent word pairs, indicating an implicit expectation that the words were bound to gender. There were no significant gender differences. However, there was an interaction between the type of word and the congruence of the word-voice pairs such that the effect of congruence of the words was amplified specifically for stereotyped names (e.g., Rachel) but not stereotyped words (e.g., football). The auditory Stroop task was adapted for 8- and 9-year-old children in a second study in which children identified the gender of the voice by pressing specific keys marked with stickers instead of speaking into a microphone. Again, there was a significant main effect for response to different word-voice pairs. Unlike the findings from the adult population, the effect of congruence on stereotypical words was stronger than for stereotypical names. This suggests that different categories of words may have different implicit associations to gender. Occupations are a critical category of stereotyped concepts and therefore warrant study of children's implicit gender associations with occupations.

\section{The Present Study}

The present research was designed first to explore how children's rudimentary implicit associations and explicit attitudes reflect gender stereotypes with a focus on occupations and second, to investigate children's explicit attitudes about a female a stereotypically masculine occupation and her male counterpart in that same occupation. We examined children's views of a female and a male firefighter-paramedic. We elected to examine 10-year-old children based on prior research on 
children's implicit and explicit attitudes about race. By age 10, implicit associations and explicit attitudes about race appear to diverge as explicit attitudes become more egalitarian (Baron \& Banaji, 2006). Moreover, implicit bias about race is amenable to change from interventions at this age but not for younger children (Gonzalez et al., 2016). Thus, children at this age may also have diverging implicit and explicit attitudes about gender representations of occupation.

To examine children's implicit gender associations, we used a modified version of the auditory Stroop task first developed by Most et al. (2007), which tests implicit gender associations of adults and 8- and 9-year old children. Researchers found that participants had a high accuracy rate in identifying the gender of a speaker and responded more quickly to voice-word pairings that were congruent and consistent with gender stereotypes as compared with incongruent voice-word pairings (Most et al., 2007). Here, the auditory Stroop task was modified to use occupations paired with male and female voices (A.S. Baron, personal communication, October 16, 2016). Because Most et al. did not find differences based on participant gender, we did not expect gender differences for our participants. Thus, in our first hypothesis, we predicted that children would have slower auditory Stroop response times to incongruent voice-occupation pairings as compared with congruent voice-occupation pairings.

Explicit gender attitudes show a developmental pattern moving from gender attitude rigidity in early childhood to increasing levels of flexible or egalitarian responses in middle childhood (Signorella \& Liben, 1985). The GenderStereotyped Attitude Scale for Children (GASC) is useful because it includes general activities (e.g., play football) and occupations (e.g., teacher). Thus, the GASC allowed us to examine the general flexibility of gender attitudes as measured by a high rate of both responses across all test items and assess the flexibility of gender attitudes specifically about occupations. In our second hypothesis, we predicted that children would be flexible regarding explicit gender stereotypes about male and female activities, including ones about occupations.

Although the current study was not an intervention study, we did introduce the same brief video episode featuring a female and a male firefighterparamedic to each child. To examine children's explicit gender attitudes of the depicted firefighterparamedics, we modified the scale accordingly (mGASC) to ask children to rate them. Previous studies using the GASC rarely found differences by participant gender and therefore we did not expect gender differences for GASC scores or mGASC scores in the current study (Signorella \& Liben, 1985). Thus, in our third hypothesis, we predicted that children's explicit gender attitudes would be flexible and egalitarian when presented with the specific case of applying gender attitudes to the firefighter-paramedics in the video.

Lastly, we investigated whether the detailed portrayal of an exemplar's professional work was strong enough to counteract the stereotype of a firefighter being a man and therefore the more competent one. To this end, we developed additional questions to determine how children evaluate the specific occupation abilities of the firefighter-paramedics in the video. In an exploratory research question, we asked how children would evaluate the female firefighter's occupation abilities and her male counterpart. In summary, we examined 10-year-old children's implicit associations and explicit gender attitudes with a focus on occupational roles.

\section{Method}

\section{Participants}

Twenty-nine girls and twenty-nine boys $\left(\mathrm{M}_{\text {age }}=10.06\right.$ years, range $=8.92$ years to 11.5 years) completed the study. Two additional tested children did not complete the study. One was not included due to parental interference and a second child was not included due to technological difficulties. We recruited participants from 3 rural, 2 suburban, and 5 urban all-purpose afterschool programs held in schools and recreation centers. Racial/ethnic identity information (provided by parents) was reported for 52 children. Of this group, 10 (19\%) had more than one race/ethnic selection. Of the remaining children, there were $42(81 \%)$ single race/ethnic group selections: 34 White/European American, 5 Latinx, 2 Black/African American, 1 Asian/Asian American.

\section{Measures}

\section{Implicit Gender Associations}

An auditory Stroop task was used (A. S. Baron, personal communication, October 16, 2016) and run using Inquisit ${ }^{\mathrm{TM}}$ version 5 lab (Millisecond software, Seattle, WA, USA). In this task participants are asked to identify if each individual word they have heard is spoken by a "girl" or a "boy." Half of the words were presented by a female voice and half by a male voice in a randomized order. Participants were instructed to press the matching key as fast as
SPRING 2021

PSI CHI JOURNAL OF PSYCHOLOGICAL RESEARCH 
they could to indicate their choice (i.e., G key for the girl voice and B key for the boy voice). The two keys were brightly labeled with stickers and aligned on the same keyboard row. Half of the participants within each gender grouping were randomly selected to use a keyboard with the girl key on the left side and the boy key on the right side; this was reversed for the remaining participants.

The auditory test stimuli included four stereotypically female occupations (e.g., secretary) and four stereotypically male occupations (e.g., engineer). Half of the voice-occupation pairings were congruent with the gender of the voice matching the gender stereotyped occupation (e.g., female voice paired with secretary) and half of the voice-occupations pairings were incongruent (e.g., female voice paired with engineer). In addition, there were four neutral test items (e.g., table) paired with female and male voices equally. The auditory stimuli were randomly presented across 48 test trials with each stimulus item being presented four times, two with a female voice and two with a male voice. Prior to the test trials, participants completed a practice session with 10 trials of neutral words that were not included in the test stimuli. The measure of implicit gender associations about occupations is based on the key press response times for congruent as compared with incongruent voice-occupation pairings. Longer response times for incongruent voice-occupation pairings than congruent voice-occupation pairings indicate implicit gender associations with occupations.

\section{Explicit Gender Attitudes}

Participants completed a three-part pen and pencil survey to assess explicit gender attitudes generally and included attitudes about occupations.

Part 1. Gender-Stereotyped Attitude Scale for Children (GASG). To examine children's explicit gender attitudes, we used the GASC developed by Signorella and Liben (1985). This widely used and adapted instrument assesses gender attitudes by asking who should do certain activities (i.e., men, women, or both men and women) rather than assessing gender knowledge by asking who does certain activities (Signorella \& Liben, 2012). The test items included a range of activities (e.g., set the kitchen table) and occupations (e.g., doctor). The current version had five fewer items than the original. Four outdated or unfamiliar test items were recommended to be eliminated by the scale authors (Signorella \& Liben, 2012) and an additional test item (i.e., use a sewing machine) was eliminated by the current authors for the same reasons. Thus, the current scale had 12 male-stereotyped items (e.g., fix a car), 11 female-stereotyped items (e.g., bake cupcakes), and seven neutral items (e.g., ride a bicycle). The stereotyped test items included six occupations and 17 other activities, later described as job and nonjob test components, respectively. The proportion of responses for both women and men are used to indicate explicit stereotype flexibility about nonjob activities. The proportion of responses for both women and men across the six occupation items are used to indicate explicit stereotype flexibility about gender and occupations.

Part 2. Modified Gender-Stereotyped Attitude Scale for Children (mGASC). To assess how gender stereotyped attitudes might be applied to the female and male firefighter-paramedics in the video, participants completed the GASC again. The same GASC test items were used; however, the survey response options were based on the names of the firefighterparamedics in the video: Kate, Jeremiah, or both Kate and Jeremiah. The proportion of responses for both Kate and Jeremiah across test items are used to indicate explicit stereotype flexibility. These findings will be referred to as the modified GASC (mGASC) results. Construct and convergent validity have been demonstrated in the original and complete form of the GASC but not the modified versions used in the current study (Signorella \& Liben, 1985).

Part 3. Occupation Ability Ratings. To determine how participants evaluated Kate and Jeremiah with respect to specific job skills, participants rated Kate and Jeremiah separately on five test items using a 7-point Likert-type scale from 1 (strongly disagree) to 7 (strongly agree). Some questions were verbatim from the video (e.g., Kate does a good job in medical emergencies) and others required more speculation (e.g., Jeremiah would make a good fire chief). In addition, participants were asked to rank who would be better for each of these test items, Kate, Jeremiah, or both Kate and Jeremiah. Similar average ratings of Kate and Jeremiah would indicate egalitarian evaluations of their professional skills.

\section{Statistical Analysis}

\section{Implicit Gender Associations}

The primary dependent variable of the auditory Stroop task was the response time latency from the onset of the auditory voice presentation to key selection (i.e., boy voice key or girl voice key). The latencies in the congruent and incongruent voice-occupation pairings were compared. Longer latencies for incongruent voice-occupation pairings compared with congruent voice-occupation pairings
JOURNAL OF PSYCHOLOGICAL RESEARCH 
indicate implicit associations. The latencies for the gender-neutral trials were not included in the main analyses and were considered separately. An additional dependent variable was included, correct or incorrect key selection (i.e., did the participant correctly identify the gender of the voice?). Latencies were only compared for correct keyed trials.

\section{Explicit Gender Attitudes}

The GASC was scored by summing the number of items in which both men and women were selected among the 23 gender-stereotyped items (Signorella \& Liben, 2012). The mGASC was scored similarly, by summing the number of items in which both Kate and Jeremiah were selected among the 23 gender-stereotyped items. The component parts of each scale were separated to focus on attitudes about occupations. The job component has six items and the nonjob component has 17 items. To compare the relative rate of selecting both Kate and Jeremiah for each component, ratio scores were computed. Ratio scores were based on the number of items in which both Kate and Jeremiah were selected divided by the total number of items for given scale component (i.e., 6 or 17). Thus, a higher ratio score indicates greater flexibility regarding attitudes about gender.

The occupation ability ratings were based on individual questions using 7-point Likert-type ratings. Higher ratings indicated greater agreement that Kate and Jeremiah were each good at the specific aspects of their jobs. The occupation ability rankings were based on who would be better for each ability, Kate, Jeremiah, or both Kate and Jeremiah. These were scored similarly to the GASC in which the number of both Kate and Jeremiah responses were tallied and the percentage of participants' both Kate and Jeremiah responses over all possible responses were computed. A higher percentage indicated an egalitarian or flexible attitude about occupation abilities.

\section{Procedure}

Following parental consent, we tested participants individually at their afterschool programs. The testing took place in a separate room away from the activities of other children. The researcher explained the procedure and indicated that the child could stop at any time and asked for their assent to continue. First, participants completed the auditory Stroop test on a laptop with headphones. Following the test, participants used a laptop with headphones to watch a brief (4.44 minute) video entitled, Kate Heckaman: FirefighterParamedic. The video was produced by PBS for their
SciGirls programming. Videos in the SciGirls series allows viewers to learn about women working in occupations that use math and science. This video introduces the viewer to two firefighter-paramedics, Kate and her partner, Jeremiah. Kate and Jeremiah can be seen doing their jobs as Kate narrates and explains the occupation and her personal story and attributes that make her good at her job (e.g., loves to learn, motivated, appreciates having an adrenaline rush). Participants were told to pay attention to the video because they would be asked questions about it later.

The final part of the study was a pencil and paper survey measuring explicit gender attitudes, including attitudes about the individuals in the video and women and men generally. Because participants saw the video before answering the questions about men and women generally, these should not be interpreted as a true "baseline" of gender attitudes. Each child was given a modest thank you gift (i.e., Slinky toy) at the completion of their participation. This research study was approved by the Bryant University Institutional Review Board on Human Subjects and the researchers complied with the APA ethical standards of treatment of sample participants.

\section{Results}

\section{Implicit Gender Associations}

We predicted that children would have slower auditory Stroop response times to incongruent voiceoccupation pairings as compared with congruent voice-occupation pairings. Our first hypothesis was not supported based on the auditory Stroop task findings. As seen in Table 1, there were no significant differences in the response times between the congruent and incongruent test trials that paired male and female voices with occupations, $t(1762)$ $=0.65, p=.52, d=0.03$. Moreover, the incongruent trials did not lead to more key selection errors than the congruent trials, $t(90)=-0.43, p=.667, d=0.09$.

As expected, the auditory Stroop findings do not indicate a difference between boys and girls in their response times between the congruent or incongruent test trials, as indicated in an analysis of variance test, $F(3,1756)=0.41, p=.75, \eta_{\mathrm{p}}{ }^{2}=0.00$. However, the gender of the voice stimuli impacted the response times. Specifically, response times for both congruent and incongruent voice-occupation pairings were slower for test trials with female voices as compared with trials with male voices, $t(1762)=$ $2.90, p=.004, d=0.14$. The slower latencies for the female voice were also found for the neutral words, $t(898.06)=16.07, p<.001, d=1.07$.
SPRING 2021

PSI CHI JOURNAL OF PSYCHOLOGICAL RESEARCH 
TABLE 1

\begin{tabular}{|c|c|c|c|c|c|}
\hline \multicolumn{6}{|c|}{$\begin{array}{l}\text { Means and Standard Deviations of Latencies in Milliseconds } \\
\text { for Auditory Stroop Trials }\end{array}$} \\
\hline $\begin{array}{l}\text { Aggregated } \\
\text { Test Trials }\end{array}$ & Test Trials & $\begin{array}{l}\text { All Children } \\
M(S D)\end{array}$ & $\begin{array}{l}\text { Boys } \\
M(S D)\end{array}$ & $\begin{array}{l}\text { Girls } \\
M(S D)\end{array}$ & $\begin{array}{l}\text { Voice } \\
\text { Effect }\end{array}$ \\
\hline \multirow{3}{*}{$\begin{array}{l}\text { Congruent } \\
\text { voice-job } \\
\text { pairings }\end{array}$} & $\begin{array}{l}\text { All congruent } \\
\text { trials }\end{array}$ & $1168.24(376.83)$ & $1166.62(370.14)$ & $1169.86(383.68)$ & \\
\hline & $\begin{array}{l}\text { Male voice- } \\
\text { Male jobs }\end{array}$ & $1139.19(383.40)$ & $1134.00(380.34)$ & $1144.29(387.15)$ & \\
\hline & $\begin{array}{l}\text { Female voice- } \\
\text { Female jobs }\end{array}$ & $1196.97(368.40)$ & $1198.95(357.66)$ & $1195.03(379.38)$ & \\
\hline \multirow{3}{*}{$\begin{array}{l}\text { Incongruent } \\
\text { voice-job } \\
\text { pairings }\end{array}$} & $\begin{array}{l}\text { All incongruent } \\
\text { trials }\end{array}$ & $1180.90(437.33)$ & $1191.24(476.27)$ & $1171.00(396.77)$ & \\
\hline & $\begin{array}{l}\text { Male voice- } \\
\text { Female jobs }\end{array}$ & $1153.23(434.47)$ & $1150.30(488.26)$ & $1155.93(422.20)$ & \\
\hline & $\begin{array}{l}\text { Female voice- } \\
\text { Male jobs }\end{array}$ & $1207.75(438.91)$ & $1229.93(499.25)$ & $1185.97(370.67)$ & \\
\hline \multicolumn{6}{|c|}{ Collapsed job pairings by voice: } \\
\hline Male voice & & $1146.09(409.11)$ & 1141.90 (414.25) & $1150.10(404.56)$ & \multirow{2}{*}{$\begin{array}{l}p=.004 \\
d=0.14\end{array}$} \\
\hline Female voice & & $1202.32(404.72)$ & $1213.86(433.95)$ & $1191.05(374.15)$ & \\
\hline \multicolumn{6}{|c|}{ Collapsed neutral pairings by voice: } \\
\hline Male voice & & $1120.84(459.78)$ & $1123.81(536.66)$ & $1117.84(367.94)$ & \multirow{2}{*}{$\begin{array}{l}p<.001 \\
d=1.07\end{array}$} \\
\hline Female voice & & $1603.78(442.82)$ & $1620.01(471.73)$ & $1587.76(412.73)$ & \\
\hline
\end{tabular}

\section{TABLE 2}

\begin{tabular}{|c|c|c|c|c|}
\hline \multicolumn{5}{|c|}{ TABLE 2} \\
\hline \multicolumn{5}{|c|}{$\begin{array}{l}\text { Ratio Scores for Gender-Stereotyped } \\
\text { Attitude Scale (GASC) and Modified Gender- } \\
\text { Stereotyped Attitude Scale (mGASC) }\end{array}$} \\
\hline $\begin{array}{l}\text { Scale and } \\
\text { Components }\end{array}$ & $\begin{array}{c}\text { All Children } \\
M(S D)\end{array}$ & $\begin{array}{l}\text { Boys } \\
M(S D)\end{array}$ & $\begin{array}{l}\text { Girls } \\
M(S D)\end{array}$ & Effect \\
\hline GASC —All items & $0.59(0.29)$ & $0.52(0.30)$ & $0.66(0.28)$ & \\
\hline GASC 一 Jobs & $0.59(0.30)$ & $0.51(0.31)$ & $0.67(0.27)$ & Gender \\
\hline GASC—Non Jobs & $0.59(0.29)$ & $0.52(0.29)$ & $0.65(0.28)$ & \\
\hline mGASC - All items & $0.52(0.34)$ & $0.43(0.32)$ & $0.61(0.34)$ & Gender Jo \\
\hline mGASC 一 Jobs & $0.48(0.35)$ & $0.40(0.33)$ & $0.56(0.35)$ & \\
\hline mGASC—Non Jobs & $0.56(0.33)$ & $0.46(0.32)$ & $0.65(0.33)$ & Gender \\
\hline
\end{tabular}

Note. GASC $=$ Gender-Stereotyped Attitude Scale for Children. $\mathrm{mGASC}=$ Modified Gender-Stereotyped Attitude Scale for Children. Ratio scores are based on the number of cases when both was selected out of all possible answers. Each scale has 23 test items consisting of two components: jobs (with 6 test items) and nonjobs (with 17 test items). The Gender Effect indicates a significant difference in the mean ratio scores between boys and girls tested with a $t$ test and at least a $p<.05$ level. The Job Effect indicates a significant difference in the mean ratio scores between job and nonjob items within the mGASC as tested with a $t$ test and having at least a $p<.05$ level.

\section{Explicit Gender Attitudes}

Next, we predicted that children would be flexible regarding explicit gender stereotypes about male and female activities, including ones about occupations. As predicted in our second hypothesis, the most frequent selection on the GASC scale was both men and women, indicating gender flexibility about stereotypical male and female activities. To examine children's gender attitudes with a focus on occupations, items related to occupations or jobs were compared with other activities or nonjob items on the scale. As seen in Table 2, children's moderate and high ratio scores reflect flexibility for both the job and nonjob items of the GASC. The ratio scores ranged from $40 \%$ when boys rated jobs on the mGASC to $67 \%$ when girls rated jobs on the GASC. Unexpectedly, girls were more flexible than boys on the job component of the GASC, $t(56)=-2.12, p=.039, d=0.55$.

We also predicted that children's explicit gender attitudes would be flexible and egalitarian when presented with the specific case of gender attitudes being applied to the firefighter-paramedics in the video. Our third hypothesis was confirmed; the most frequent selection on the mGASC scale was both Kate and Jeremiah (56\%), indicating a general flexibility about activities and gender. Next, we examined attitudes about occupations more closely in a paired-samples $t$ test. As seen in Table 2, there was more flexibility for the nonjob items (i.e., 56\%) as compared with the job items (i.e., $48 \%$ ) for Kate and Jeremiah on the mGASC, $t(56)=-2.90, p=.005, d=0.24$.

We predicted that boys and girls would have similar explicit attitudes; however, the independentsamples $t$ test GASC findings were mixed on this prediction. As seen in Table 2, the collapsed GASC scores did not differ significantly for boys and girls, $t(56)=-1.94, p=.058, d=-0.48$. We did observe a significant gender difference for the collapsed mGASC scores, with girls having higher ratio scores, or more flexible gender attitudes as compared with boys, $t(56)=-2.19, p=.033, d=0.54$. In contrast to the GASC findings, girls did not demonstrate significantly more stereotype flexibility than boys in the job components of the mGASC, $t(56)=-1.78$, $p=.080, d=0.55$, but girls were more flexible than boys in the nonjobs component of the mGASC scale, $t(56)=-2.23, p=.030, d=0.58$.

Children did not uniformly select both across all six jobs. Children had the highest level of stereotype flexibility for doctor in which 25 out of 28 boys responded and 26 out of 29 girls responded that 
both men and women should be a doctor. Fewer children responded that both Kate and Jeremiah should be a doctor; specifically, 12 boys and 19 girls. The lowest level of gender stereotype flexibility was for ballet dancer/teacher in which 8 out of 27 boys responded and 16 out of 28 girls responded both men and women should be a ballet dancer/teacher. Even fewer responded that both Kate and Jeremiah should be a ballet dancer/teacher, that is 4 boys and 10 girls. There were few cases where children responded that men $(n=1)$ or Jeremiah $(n=8)$ should be a ballet dancer/teacher; boys made the counter-stereotyped option for 7 of these 9 cases.

Lastly, in an exploratory research question, we asked how children would evaluate the female firefighter's occupation abilities and the occupation abilities of her male counterpart. The occupation ability ratings were high for both Kate and Jeremiah, with Kate's average ratings always higher than Jeremiah's ratings (see Table 3 ). The range of ratings on a 7-point scale was 5.86 to 6.76 for Kate and 5.14 to 6.41 for Jeremiah. Children endorsed Kate's abilities more positively than Jeremiah when judging her being good in medical emergencies, $t(106.22)=$ 2.49, $p=.014, d=0.46$, and being good at saving lives in a fire, $t(86.42)=2.27, p=.026, d=0.42$. When children were asked questions about who would be better at doing their job, Kate, Jeremiah, or both Kate and Jeremiah, the most frequent response was both Kate and Jeremiah as seen in Table 3. Moreover, children frequently selected Kate as a second choice after both for these questions. For example, $91 \%$ of children selected Kate or both for who would be a better fire chief. Unlike the ability ratings, there were gender differences for ability rankings with girls always selecting both more often than boys. In four out of six of the rankings, the difference was significant, as tested by Fisher Exact and Chi-square tests. The greatest ranking disparity was found in the case of the question of who would be a better fire chief. The choice of both was selected by $38 \%$ of boys and $75 \%$ for girls, $\chi^{2}=8.97[2,57], p=.011, d=0.69$.

\section{Discussion}

In the present study, we expected to demonstrate that children have implicit associations that strictly link occupations with one's gender. Our findings did not support this prediction and the possible explanation for this unexpected finding is considered here. Although prior research with 10-year-old children has demonstrated the pervasiveness of implicit gender-biased attitudes (Dunham et al., 2015), our findings suggest that implicit associations may not be present in all domains. Other researchers may dispute this conclusion given the findings from two other studies with children in middle childhood that revealed children's implicit gender associations regarding occupations.

In one of the studies, 8- and 9-year-old children were asked to generate sentences with gender stereotypical name-occupation pairings (Henry-auto mechanic) and generate sentences with counter stereotypical pairings (e.g., Henry-nurse; Wilbourn \& Kee, 2010). Across several measures, including mean response latency, children demonstrated

\section{TABLE 3}

\begin{tabular}{|c|c|c|c|c|c|c|}
\hline \multicolumn{7}{|c|}{ TABLE 3} \\
\hline \multicolumn{7}{|c|}{ Occupation Ability Ratings and Rankings } \\
\hline $\begin{array}{l}\text { Occupation Ability Ratings } \\
\text { (scale 1-7) }\end{array}$ & $\begin{array}{l}\text { All Children } \\
M(S D)\end{array}$ & $d$ & $\begin{array}{l}\text { Boys } \\
M(S D)\end{array}$ & $d$ & $\begin{array}{l}\text { Girls } \\
M(S D)\end{array}$ & $d$ \\
\hline $\begin{array}{l}\text { Kate is good at her job as } \\
\text { a firefighter/paramedic } \\
\text { Jeremiah is good at his job as } \\
\text { a firefighter/paramedic }\end{array}$ & $\begin{array}{l}6.47(0.78) \\
6.16(1.07)\end{array}$ & & $6.48(0.95)$ & & $\begin{array}{l}6.45(0.57) \\
6.07(0.75)\end{array}$ & $0.57^{\mathrm{a}}$ \\
\hline $\begin{array}{l}\text { Kate is good at her job } \\
\text { in medical emergencies } \\
\text { Jeremiah is good at his job } \\
\text { in medical emergencies }\end{array}$ & $6.14(1.15)$ & $0.46^{\mathrm{a}}$ & $6.03(1.40)$ & $0.55^{\mathrm{a}}$ & $6.24(0.83)$ & \\
\hline $\begin{array}{l}\text { Kate is good at saving } \\
\text { lives when there is a fire } \\
\text { Jeremiah is good at saving } \\
\text { lives when there is a fire }\end{array}$ & $6.71(0.68)$ & $0.42^{\mathrm{a}}$ & $6.76(0.79)$ & & $6.66(0.55)$ & \\
\hline $\begin{array}{l}\text { Kate is good at being part of } \\
\text { the team of firefighters/paramedics } \\
\text { Jeremiah is good at being part of } \\
\text { the team of firefighters/paramedics }\end{array}$ & $\begin{array}{l}6.57(1.04) \\
6.26(1.18)\end{array}$ & & $\begin{array}{l}6.52(1.33) \\
6.17(1.51)\end{array}$ & & $\begin{array}{l}6.62(0.68) \\
6.34(0.72)\end{array}$ & \\
\hline $\begin{array}{l}\text { Kate would be a good fire chief } \\
\text { Jeremiah would be a good fire chief }\end{array}$ & $\begin{array}{l}6.14(1.34) \\
5.74(1.45)\end{array}$ & & $\begin{array}{l}5.86(1.74) \\
5.45(1.72)\end{array}$ & & $\begin{array}{l}6.41(0.73) \\
6.03(1.05)\end{array}$ & \\
\hline $\begin{array}{l}\text { Occupation Ability Rankings } \\
\text { (Percentage both selected) }\end{array}$ & All Children & $d$ & Boys & $d$ & Girls & $d$ \\
\hline $\begin{array}{l}\text { Who does a better job as } \\
\text { a firefighter/paramedic? }\end{array}$ & 72 & $0.58^{b}$ & 59 & & 86 & \\
\hline $\begin{array}{l}\text { Who does a better job } \\
\text { in medical emergencies? }\end{array}$ & 64 & $0.56^{\mathrm{b}}$ & 52 & & 76 & \\
\hline $\begin{array}{l}\text { Who does a better job at saving } \\
\text { lives when there is a fire? }\end{array}$ & 79 & $0.57^{\mathrm{b}}$ & 69 & & 90 & \\
\hline $\begin{array}{l}\text { Who would you choose to save } \\
\text { someone from a burning building? }\end{array}$ & 53 & & 52 & & 55 & \\
\hline $\begin{array}{l}\text { Who is better at being part of a } \\
\text { team of firefighters/paramedics? }\end{array}$ & 90 & & 83 & & 97 & \\
\hline Who would be a better fire chief? & 56 & $0.69^{b}$ & 38 & & 75 & \\
\hline $\begin{array}{l}\text { Note. The a superscript indicates a sig } \\
\text { Kate and Jeremiah as tested with an } \\
\text { shown in the cases of significant diff } \\
\text { percentages of the occupation ability } \\
\text { Exact tests with at least at the } p<.0 \\
\text { differences. }\end{array}$ & $\begin{array}{l}\text { icant difference } \\
\text { JOVA with at lea } \\
\text { nces. The }{ }^{b} \text { supe } \\
\text { inkings betwee } \\
\text { evel. Cohen's } d\end{array}$ & $\begin{array}{l}\text { e in the r } \\
\text { ast a } p< \\
\text { erscript } \\
\text { n boys a } \\
\text { effect si }\end{array}$ & $\begin{array}{l}\text { nean occupati } \\
.05 \text { level. Coh } \\
\text { ndicates a sig } \\
\text { nd girls as tes } \\
\text { es are only sh }\end{array}$ & $\begin{array}{l}n \text { ability } \\
\text { n's } d \text { eff } \\
\text { ficant } g \\
\text { d with } \\
\text { wn in th }\end{array}$ & $\begin{array}{l}\text { ratings betw } \\
\text { ect sizes are or } \\
\text { ender differen } \\
\text { Chi-Square an } \\
\text { e cases of sigr }\end{array}$ & $\begin{array}{l}\text { en } \\
\text { ly } \\
\text { ce in the } \\
\text { Fisher } \\
\text { ificant }\end{array}$ \\
\hline
\end{tabular}


the greatest difficulty when males were paired with traditionally female occupations. Moreover, children often manipulated the counter-stereotyped information to fit with gender stereotypes. When presented with a female name and a stereotypically male occupation, some children would manipulate the sentence to either change the gender of the person (i.e., "Julie the Police Officer" became "Julian the police officer fights crime"), or a part of the occupation (i.e., "Henry the nurse is a doctor, too; Wilbourn \& Kee, 2010). In another study that measured response time to assess implicit gender associations with occupations, participants were asked whether individually presented occupations paired with kinship terms they heard could describe the same person (Siyanova-Chanturia et al., 2015). For example, could "engineer-sister" describe the same person? Children in 8-year-old and 10-year-old groups and adults more consistently responded "yes" and did so more quickly for stereotypically congruent word pairings than incongruent pairings. The testing methods differed from the current study in which Most et al.'s (2007) auditory Stroop task was adapted.

Indeed, Siyanova-Chanturia et al. (2015) had noted problems with the Most et al. task methodology. One concern was that there was no coherent rationale for the mix of target words used in the Most et al. study. This was not a problem in the adaptation we used because all of our target words were occupations. Yet, like Most et al. (2007), we did not control the lexical properties of words. In the Siyanova-Chanturia et al. (2015) study, auditory stimuli were carefully constructed, fully synthesized, neutral and natural sounding voices. In addition, it is worth noting that our adapted auditory Stroop task was designed to be easy enough to be used by young preschool children. Therefore, our 10-year-old participants might have found that the incongruent trials were not very difficult to process and therefore took about the same amount of time to react to the auditory cues in the congruent and incongruent trials. In summary, the current results indicated that children do not have implicit gender associations about occupations.

The lack of control of the lexical properties of the auditory Stroop task used in the current study may partially explain the unforeseen finding that participants' responses to the male voices were significantly faster than their responses to the female voices, independent of occupation pairing. Prior research on the perception of voices has indicated that people are sensitive to voice characteristics and make important evaluations based on voice qualities associated with gender (Doubleday \& Lee, 2016). For example, it has been found that voicebased biases favoring men can affect how health professionals are evaluated. Relatively low pitch in voices, associated with masculinity, is preferred for both male and female voices when individuals are making hypothetical leadership choices (Anderson \& Klofstad, 2012). Voice qualities have also affected hypothetical hiring decisions. Men and women using low pitched, creaky voices known as vocal fry, are evaluated poorly overall and less hirable than others; the poor evaluations were stronger for female voices (Anderson et al., 2014). Variations in female voice quality based on pitch and formant spacing has been shown to affect adults' perception of social traits (Levitt \& Lucas, 2016). In other words, characteristics of voice stimuli matter and the children in the current study responded more quickly to the male voice as compared with the female voice most likely due to the differences in the unmeasured lexical qualities of the voice stimuli.

Regarding explicit attitudes, children in our study were generally flexible as predicted, which is consistent with the findings for children's implicit associations. On both the GASC and mGASC, the most common choice was both. The findings merit a cautious interpretation because children were presented the video prior to answering questions on both forms of the GASC, and it might have impacted not only the views about Kate and Jeremiah but also about men and women generally. There were unexpected gender differences on these scales, but they were not uniformly present across scales or component parts. Nevertheless, in each case of a gender difference, girls had greater attitude flexibility than boys. Thus, our prediction that there would be no gender differences might have been based too strictly on the research findings from an earlier time when the GASC was developed (Signorella \& Liben, 1985).

Other explicit measures of gender attitudes commonly find that girls have more flexible gender attitudes than boys. A notable example comes from the recent meta-analytical study of the Draw a Scientist methodology (Miller et al., 2018). In this methodology, children were prompted to draw a scientist; $96 \%$ of the boys drew a male scientist, whereas only $58 \%$ of the girls drew a male scientist. These results reflect a meaningful shift toward an equalitarian perspective, particularly for the girls. In the original Chambers (1983) study, only 28 out of 5,000 children selected a woman as a scientist. 
Children in the current study differed in how flexibly they linked gender with occupations as a function of the occupations themselves. This linking may be due in part to children's exposure to different samples of careers. It is likely that most children in middle childhood have seen women and men in a range of professional roles, more so than in earlier decades. As a point of reference, $60 \%$ of pediatricians were female compared to $33 \%$ of physicians overall who were female in the United States as of 2013 (AAMC, 2014). As a result, children may be more readily accepting of female doctors than other counter-stereotypical examples. In our study, doctor was the most flexible career item among boys and girls. The lowest level of gender stereotype flexibility was found for the ballet teacher/dancer item, supporting prior research that roles for men are more restrictive and tightly held than roles for women (Blakemore, 2003; De Visser \& McDonnell, 2013; Henshaw et al., 1992; Wilbourn \& Kee, 2010). This also makes sense because professional roles are not equally occupied by women and men and children can see this for themselves.

Children's evaluations focusing on the firefighter-paramedics shown in the video make clear that the female professional was evaluated equally or more favorably than her male counterpart. For example, participants rated Kate as better than Jeremiah in medical emergencies, possibly because Kate mentioned her prior work in a hospital as an occupational therapist. When asked who would be a better fire chief, participants chose Kate or both $89 \%$ of the time. Although this could reflect that there are more women firefighters, we doubt this explanation because only $\sim 8 \%$ of firefighters in the United States are women (National Fire Protection Association, 2020). Thus, we interpret this finding to reflect the short-term benefits of viewing counter-stereotypical examples of occupational roles. Because Jeremiah did not have a speaking role, Kate's expertise as a firefighter was clearly the focus of this video. Alternatively, if children had interpreted Jeremiah as the better leader, that might have reflected that even knowing Kate's expertise did not outweigh Jeremiah's presence as a man.

\section{Limitations and Strengths}

The novel auditory Stroop task is an inadequate test for the current study goals and might have revealed more about voice and gender associations than occupation and gender associations. Therefore, it is not recommended for future tests of genderoccupation associations.
The findings pertaining to children's explicit attitudes should be considered in the context of the following methodological limitations. First, there were no contrasting conditions; either pre- and postvideo exposure or exposed versus nonvideo exposed condition. Second, the video was presented before both forms of the GASC and might have impacted not only attitudes about Kate and Jeremiah but also women and men generally. Third, the implicit association and explicit occupation attitude measures did not include exemplars of firefighter or paramedic. These test items could have been used as an approximation of how much children associated firefighters and paramedics with men, women, or both. Fourth, the video only included a female in a counter stereotypical occupation and not a male in a counter stereotypical occupation. A fifth study limitation is that the occupational status of the parents of participants in this small sample was not available. Parents are children's primary models for occupational and other roles. Unfortunately, the impact of parental employment generally and regarding counter-stereotypical employment specifically, could not be examined. Ultimately, the study limitations can guide future research.

Despite these limitations, this study has several notable strengths. We selected a readily available and high-quality video from the PBS SciGirls series that was developed about women in science and science careers and consider its counter-stereotypical depiction of a firefighter-paramedic. This video featured Kate, a firefighter who described her job and successes, and Jeremiah, her firefighter partner who did not have an active role. By modifying the GASC, we were able to assess attitudes toward the specific woman featured in the video and determine that children overwhelmingly saw her as a potentially good fire chief (vs. Jeremiah). Another strength of the sample in spite of its small size was its racial and ethnic diversity.

\section{Future Research Implications}

It would be constructive to examine children's thinking about equalitarian occupational roles that were demonstrated in the current study. Do children respond to queries about who should have a job based on what they see in the world or what they would like to see? If it is what they would like to see, why would they choose to see gender equality in the world? Examining parental role models and parental messaging along with measuring children's attitudes about what is fair may help to tease apart if they are describing what they see or what they
SPRING 2021

PSI CHI JOURNAL OF PSYCHOLOGICAL RESEARCH 
believe is right and should happen.

In addition, a continued focus on women in counter stereotypical occupations is valuable if done with experimental controls. The Sci Girls series is particularly strong because they include many different types of women, beyond the idealized European American woman who is often represented as the "standard" woman for many issues (i.e., gender pay gap). Thus, future studies can broaden our understanding of gender attitudes by looking at the breadth of gendered experiences rather than one type of women's experiences.

Research focusing on children's attitudes about males in counter-stereotypic careers is also warranted. In our study, ballet teacher/dancer was the most stereotyped item as the participants said that Jeremiah should be a ballet teacher/dancer only $25 \%$ of the time. A study examining longitudinal labor force trends in the United States from 1950 to 2000 found evidence to support the theory that work done by women is devalued in the labor force causing occupation-wide inequities in wages (Levanon et al., 2009).

Future research that explores the impact of counter stereotypic exemplars on gender biases is particularly important given that flexible attitudes are not comprehensive across all occupations and other domains of potential bias. Prior research has highlighted that reading fiction can influence readers' real-world beliefs and even promote more acceptance of interpersonal differences (Xu et al., 2013). Thus, future work may focus on encouraging children to read fiction featuring counterstereotypical occupation models as a method of broadening children's gender flexibility. Others have recommended that elementary schools create programs that invite wide arrays of professionals to visit (Chambers et al., 2018). Such efforts need to carefully counteract stereotypes rather than reinforce them. An illustration of this need can be found in a recent example when a preschool child told her mother that girls could not be firefighters since that is what she saw in books (Ritschel, 2019). The parent's social media request for images and books with female firefighters was profoundly successful, with countless professionals sharing book suggestions and their personal pictures. This opportunity needs to be widely available to children and there are programs that are doing just this. For example, Rice University's Institute for Biosciences and Bioengineering in Houston, Texas hosts a

SPRING 202

PSI CHI

JOURNAL OF PSYCHOLOGICAL RESEARCH research across disciplines. They are paired in small groups with mentors (many of whom are also young women) who demonstrate their research, teach basic techniques, and answer any questions they have about pursuing STEM in college. In sum, abundant and richly detailed counter stereotypical models can offer opportunities to overcome generalized gender biases about occupations.

\section{References}

Anderson, R. C., \& Klofstad, C. A. (2012). Preference for leaders with masculine voices holds in the case of feminine leadership roles. PLOS ONE, 7(12), e51216. https://doi.org/10.1371/journal.pone.0051216

Anderson, R. C., Klofstad, C. A., Mayew, W. J, \& Venkatachalam, M. (2014). Vocal fry may undermine the success of young women in the labor market. PLOS ONE, 9(5), e97506. https://doi.org/10.1371/journal.pone.0097506

Baron A. S., \& Banaji, M. R. (2006). The development of implicit attitudes. Evidence of race evaluations from ages 6 and 10 and adulthood. Psychological Science, 17(1), 53-58. https://doi.org/10.1111//.1467-9280.2005.01664.x

Blakemore, J. E. W. (2003). Children's beliefs about violating gender norms: Boys shouldn't look like girls, and girls shouldn't act like boys. Sex Roles, 48(9), 411-419. https://doi.org/10.1023/A:1023574427720

Carney, R. R., Nosek, B. A., Greenwald, A. G., \& Banaji, M. R. (2007). The Implicit Association Test (IAT). In R. F. Baumeister and K. D Vohs (Eds.), Encyclopedia of social psychology, (pp. 463-464). Sage.

Carter, D. B., \& Patterson, C. J. (1982). Sex roles as social conventions: The development of children's conception of sex-role stereotypes. Developmental Psychology, 18(6), 812-824. https://doi.org/10.1037/0012-1649.18.6.812

Chambers, D. W. (1983). Stereotypic images of the scientist: The draw-ascientist test. Science Education, 67(2), 255-265. https://doi.org/10.1002/sce.3730670213

Chambers, N., Kashefpakdel, E. T., Rehill, J., \& Percy, C. (2018). Drawing the future: Exploring the career aspirations of primary school children from around the world. Education and Employers.

Cvencek, D., Meltzoff, A. N., \& Greenwald, A. G. (2011). Math-gender stereotypes in elementary school children. Child Development, 82(3), 766-779. https://doi.org/10.1111/j.1467-8624.2010.01529.x

De Visser, R. 0., \& McDonnell, E. J. (2013). 'Man points': Masculine capital and young men's health. Health Psychology, 32(1), 5-14. https://doi.org/10.1037/a0029045

Doubleday, A. F., \& Lee, L. M. J. (2016). Dissecting the voice: Health professions students' perceptions of instructor age and gender in an online environment and the impact on evaluations for faculty. Anatomical Sciences Education, 9(6), 537-544. https://doi.org/10.1002/ase.1609

Dunham, Y., Baron, A. S., \& Banaji, M. R. (2015). The development of implicit gender attitudes. Developmental Science, 19(5), 781-789. https://doi.org/10.1111/desc.12321

Dunham, Y., Baron, A. S., \& Carey, S. (2011). Consequences of 'minimal' group affiliations in children. Child Development, 82(3), 793-811. https://doi.org/10.1111/j.1467-8624.2011.01577.x

Eagly, A. H. (1987). Sex differences in social behavior: A social-role interpretation. Erlbaum.

Garrett, C. S., Ein, P. L., \& Tremaine, L. (1977). The development of gender stereotyping of adult occupations in elementary school children. Child Development, 48(2), 507-512. https://doi.org/10.2307/1128646

Glick, P., \& Fiske, S. T. (1999). Gender, power dynamics, and social interaction. In M. M. Ferree, J. Lorber, \& B. Hess (Eds.), Revisioning gender: The gender lens (Vol. 5, pp. 365-398). Sage.

Greenwald, A. G., \& Banaji, M. R. (1995). Implicit social cognition: Attitudes, selfesteem, and stereotypes. Psychological Review, 102(1), 4-4. https://doi.org/10.1037/0033-295X.102.1.4

Greenwald, A. G., McGhee, D. E., \& Schwartz, J. K. L. (1998). Measuring individual differences in implicit cognition: The implicit association test. Journal of Personality and Social Psychology, 74(6), 1464-1480. https://doi.org/10.1037/0022-3514.74.6.1464 
Greenwald, A. G., Poehlman, T. A., Uhlmann, E. L., \& Banaji, M. R. (2009). Understanding and using the implicit association test: III. Meta-analysis of predictive validity. Journal of Personality and Social Psychology, 97(1), 17-41. https://doi.org/10.1037/a0015575

Gonzalez, A. M., Steele, J. R., \& Baron, A. S. (2016). Reducing children's implicit racial bias through exposure to positive out-group exemplars. Child Development, 88(1), 123-130. https://doi.org/10.1111/cdev.12582

Halim, M. L." Ruble, D. N., Tamis-LeMonda, C. S., Shrout, P. E. \& Amodio, D. M. (2017). Gender attitudes in early childhood: Behavioral consequences and cognitive antecedents. Child Development, 88(3), 882-899. https://doi.org/10.1111/cdev.12642

Hayes, A. R., Bigler, R. S., Weisgram, E. S. (2018). Of men and money: Characteristics of occupations that affect the gender differentiation of children's occupational interests. Sex Roles, 78(11-12), 775-788. https://doi.org/10.1007/s11199-017-0846-8

Henshaw, A., Kelly, J., \& Gratton, C. (1992). Skipping's for girls: Children's perceptions of gender roles and gender preferences. Educational Research, 34(3), 229-35. https://doi.org/10.1080/0013188920340307

Holler, M. (2013, August 5). Leaning in to Lego camp. New York Times [Web log post]. https://parenting.blogs.nytimes.com/2013/08/05/leaning-in-tolego-camp/

Huston, A. C. (1983). Sex-typing. In E. M. Hetherington (Vol. Ed.), Socialization, personality, and social development (pp. 387-468), in P. H. Mussen (Ed.), The Handbook of child psychology. Wiley.

Hyde, J. S., Lindberg, S. M., Linn, M. C., Ellis, A. B., \& Williams, C. C. (2008), Gender similarities characterize math performance. Science, 321(5888), 494-495. https://doi.org/10.1126/science.1160364

Levanon, A., England, $P_{1,}$ \& Allison, P. (2009). Occupational feminization and pay: Assessing causal dynamics using 1950-2000 U.S. census data. Social Forces, 88(2), 865-891. https://doi.org/10.1353/sof.0.0264

Levitt, A. G., \& Lucas, M. (2016). The effects of four voice qualities on the perception of a female voice. Wellesley College Digital Scholarship and Archive. https://repository.wellesley.edu/object/ir248

Liben, L. S., Bigler, R. S., \& Krogh, H. R. (2001). Pink and blue collar jobs: Children's judgments of job status and job aspirations in relation to sex of worker. Journal of Experimental Child Psychology, 79(4), 346-363. https://doi.org/10.1006/jecp.2000.2611

Liben, L. S., Bigler, R. S., \& Krogh, H. R. (2002). Language at work: Children's gendered interpretations of occupational titles. Child Development, $73(3)$ 810-828. https://doi.org/10.1111/1467-8624.00440

Miller, D. I., Nolla, K. M., Eagly, A. H., \& Uttal, D. H. (2018). The development of children's gender-science stereotypes: A meta-analysis of 5 decades of U.S. Draw-A-Scientist studies. Child Development, 89(6), 1943-1955. https://doi.org/10.1111/cdev.13039

Most, S. B., Sorber, A. V. \& Cunningham, J. G. (2007). Auditory Stroop reveals implicit gender associations in adults and children. Journal of Experimental Social Psychology, 43(2), 287-294, https://doi.org/10.1016/j.jesp.2006.02.002

Mulvey, K. L. \& Killen, M. (2015). Challenging gender stereotypes: Resistance and exclusion. Child Development, 86(3), 681-694. https://doi.org/10.1111/cdev.12317

National Fire Protection Association. (2020). US Fire Department Profile 2018. Retrieved from https://www.nfpa.org/-/media/Files/News-and-Research/ Fire-statistics-and-reports/Emergency-responders/osfdprofile.pdf

Oswald, F. L., Mitchell, G., Blanton, H., Jaccard, J., \& Tetlock, P. E. (2013). Predicting ethnic and racial discrimination: A meta-analysis of IAT criterion studies. Journal of Personality and Social Psychology, 105(2), 171-192. https://doi.org/10.1037/a0032734

Rae, J. R., \& Olson, K. R. (2018). Test-retest reliability and predictive validity of the Implicit Association Test in children. Developmental Psychology, 54(2), 308-330. https://doi.org/10.1037/dev0000437
Räty, H., Vänskä, J., Kasanen, K., \& Kärkkäinen, R. (2002). Parents' explanations of their child's performance in mathematics and reading: A replication and extension of Yee and Eccles. Sex Roles, 46(3), 121-128. https://doi.org/10.1023/A:1016573627828

Ritschel, C. (2019, January 20). Female firefighters send photos and videos of themselves to four-year-old to prove women can do the job. Independent.

Ruble, D. N., Martin, C., \& Berenbaum, S. (2006). Gender development. In N. Eisenberg (Eds.), Handbook of child psychology: Personality and social development, Vol. 3, (pp. 858-932). Wiley.

Signorella, M. L., \& Liben, L. S. (2012/1980). A summary of procedures for administering the Gender-Stereotyped Attitude Scale for Children (GASC). PSycTESTS, https://doi.org/10.1037/t09185-000

Signorella, M. L., \& Liben, L. S. (1985). Assessing children's gender-stereotyped attitudes. Psychological Documents, 15,7 . http://www.personal.psu.edu/users/s/d/sdq/articles/gasc.html

Skočajić, M. M., Radosavljević, J. G., Okičić, M. G., Janković, I. O., \& Žeželj, I. L. (2019). Boys just don't! Gender stereotyping and sanctioning of counterstereotypical behavior in preschoolers. Sex Roles, 82(2), 163-172 https://doi.org/10.1007/s11199-019-01051-x

Skowronski, J. J., \& Lawrence, M. A. (2001). A comparative study of the implicit and explicit gender attitudes of children and college students. Psychology of Women Quarterly, 25(2), 155-165. https://doi.org/10.1111/1471-6402.00017

Siyanova-Chanturia A., Warren P., Pesciarelli F., Cacciari C. (2015). Gender stereotypes across the ages: On-line processing in school-age children, young and older adults. Frontiers in Psychology, 6, 1388. https://doi.org/10.3389/fpsyg.2015.01388

Stroop, J. R. (1935). Studies of interference in serial verbal reactions. Journal of Experimental Psychology, 18(6), 643-661. https://doi.org/10.1037/h0054651

Vervecken, D., \& Hannover, B. (2015). Yes I can! Effects of gender fair job descriptions on children's perceptions of job status, job difficulty, and vocational self-efficacy. Social Psychology, 46(2), 76-92. https://doi.org/10.1027/1864-9335/a000229

Weisgram, E. S., Bigler, R. S., \& Liben, L. S. (2010). Gender, values, and occupational interests among children, adolescents, and adults. Child Development, 81(3), 778-796. https://doi.org/10.1111/j.1467-8624.2010.01433.x

Wilbourn, M. P. \& Kee, D. W. (2010). Henry the nurse is a doctor too: Implicitly examining children's gender stereotypes for male and female occupational roles. Sex Roles, 62(5), 670-683. https://doi.org/10.1007/s11199-010-9773-7

$\mathrm{Xu}_{1} \mathrm{X}_{\mathrm{u}}, \mathrm{Mar}_{1}$ R. A $\mathrm{u}_{\mathrm{u}}$ \& Peterson, J. B. (2013). Does cultural exposure partially explain the association between personality and political orientation? Personality and Social Psychology Bulletin, 39(11), 1497-1517. https://doi.org/10.1177/0146167213499235

Author Note. Ryan Brown (ib https://orcid.org/0000-00032844-5928

Nanci Weinberger (iD https://orcid.org/0000-0002-2085-0518 Ryan Brown is now at the Department of Psychological Sciences, Rice University, Houston, TX.

We thank the following organizations and individuals for their help: SciGirls (PBS) for permission to use a SciGirls episode; Dr. Steven Lacey, Carroll School of Management, Boston College, for assistance in implementing the test software; Nina Luiggi for assistance with data collection; afterschool administrators and teachers for facilitating data collection at their programs; and the children and families who participated in the study.

Correspondence concerning this article should be addressed to Ryan Brown, Department of Psychological Sciences, Rice University. Email: rlb11@rice.edu
SPRING 202 


\section{Psi Chi Journal of Psychological Research 2020 Reviewers}

We sincerely appreciate the hard work on the part of the following individuals who each completed at least one review in 2020. Without the assistance of such dedicated professionals, Psi Chi Journal would not be able to function.-Debi Brannan (Editor)

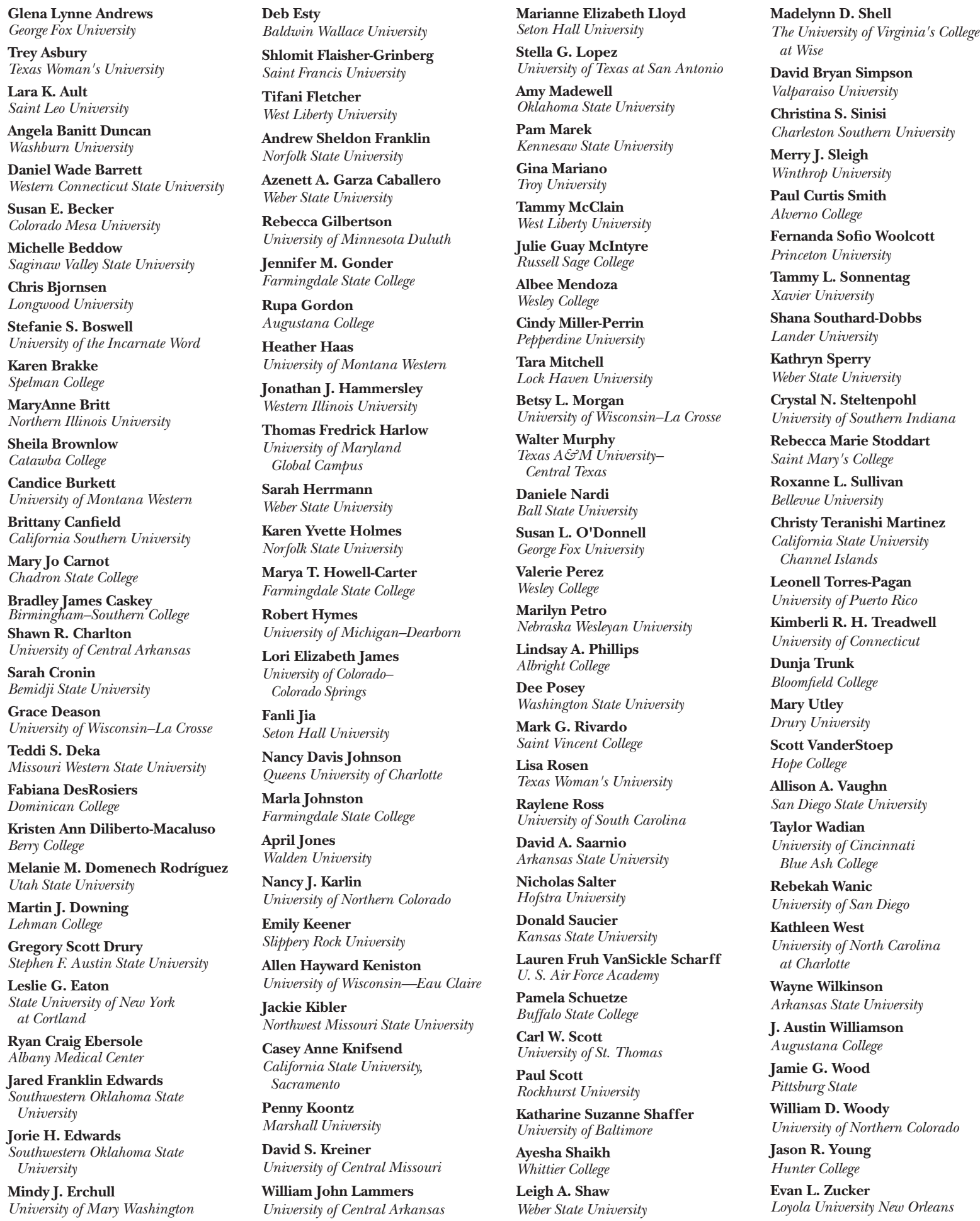




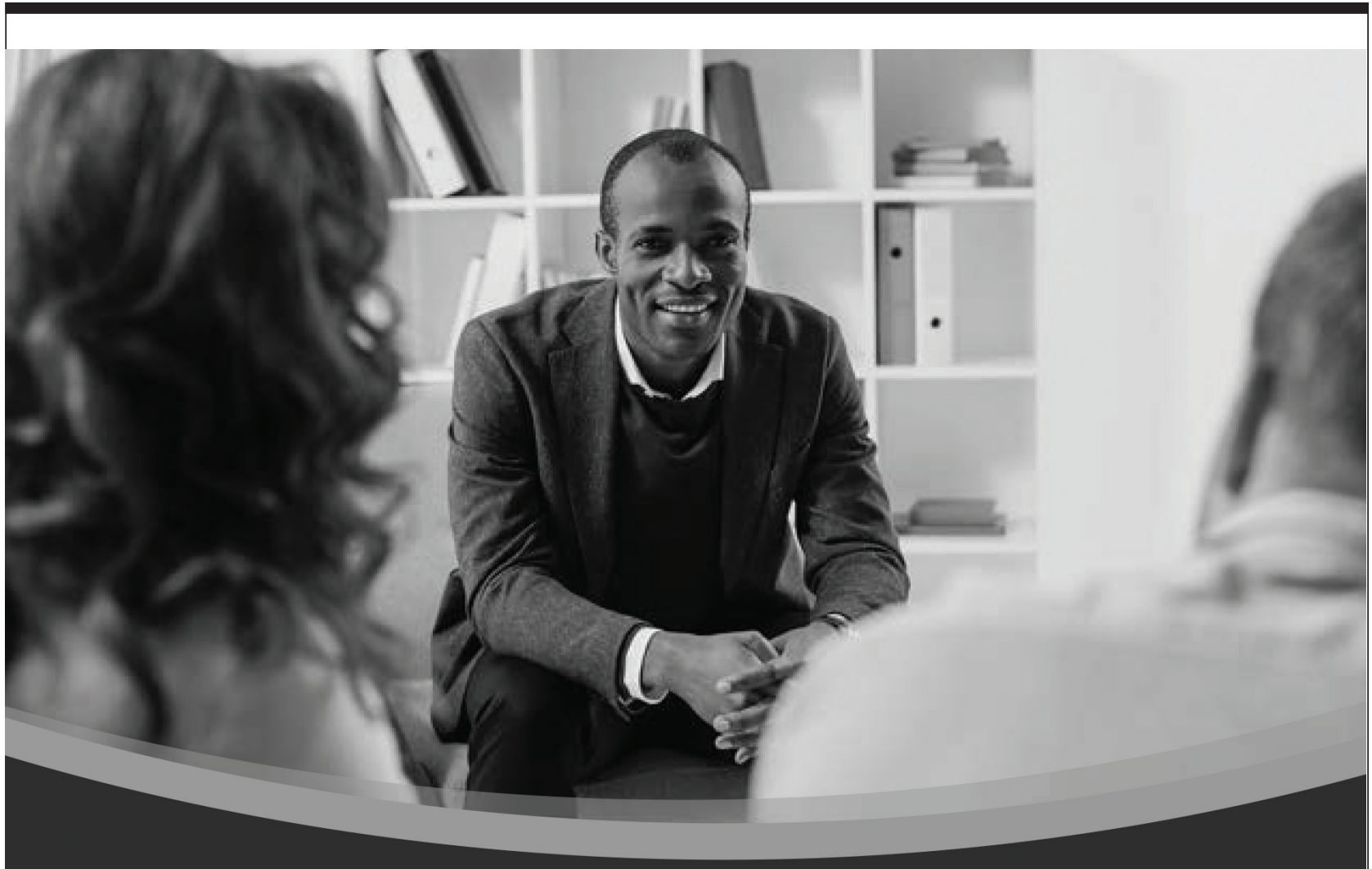

\section{Your Career in Psychology Starts Here}

\section{Choose your path:}

Clinical Psychologists • Marriage and Family Therapists • Clinical Counselors

- Organizational Psychologists • Organizational Behavior Psychologists • Organizational Development Psychologists • Psychopharmacologists 


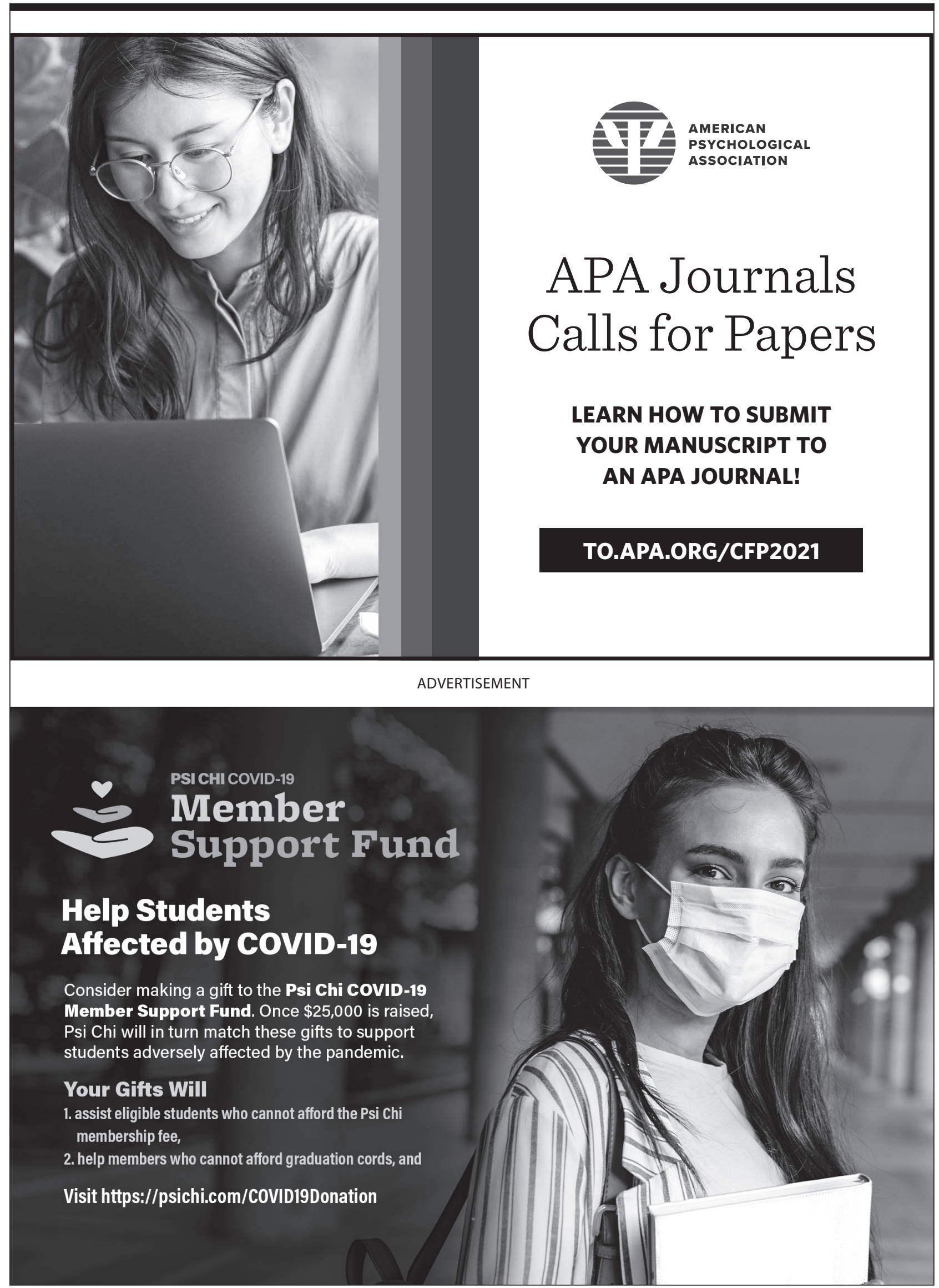

SPRING 2021

PSI CHI

JOURNAL OF PSYCHOLOGICAL RESEARCH 


\section{Publish Your Research in Psi Chi Journal}

Undergraduate, graduate, and faculty submissions are welcome year round. Only one author (either first author or coauthor) is required to be a Psi Chi member. All submissions are free. Reasons to submit include

- a unique, doctoral-level, peer-review process

- $\quad$ indexing in PsycINFO, EBSCO, and Crossref databases

- free access of all articles at psichi.org

- $\quad$ our efficient online submissions portal

View Submission Guidelines and submit your research at www.psichi,org/?page=JN_Submissions

\section{Become a Journal Reviewer}

Doctoral-level faculty in psychology and related fields who are passionate about educating others on conducting and reporting quality empirical research are invited become reviewers for Psi Chi Journal. Our editorial team is uniquely dedicated to mentorship and promoting professional development of our authors-Please join us!

To become a reviewer, visit www.psichi,org/page/JN_BecomeAReviewer

\section{Resources for Student Research}

Looking for solid examples of student manuscripts and educational editorials about conducting psychological research? Download as many free articles to share in your classrooms as you would like.

Search past issues, or articles by subject area or author at www.psichi,org/journal_past

\section{Add Our Journal to Your Library}

Ask your librarian to store Psi Chi Journal issues in a database at your local institution. Librarians may also e-mail to request notifications when new issues are released.

Contact PsiChiJournal@psichi.org for more information. 